\title{
EXPERIÊNCIAS NA APLICAÇÃO DE TESTES DE USABILIDADE EM AMBIENTES EDUCACIONAIS: AVALIAÇÃO DE REA EM FORMATO DE CASOS CLÍNICOS
}

BRASÍLIA/DF JULHO/2018

\author{
Marcio Batista da Silva - UNA-SUS - marciosilva@unasus.gov.br \\ Luciana Dantas Soares Alves - UNA-SUS - lucianaalves@unasus.gov.br \\ Laura Gris Mota - UNA-SUS - lauramota@unasus.gov.br \\ Tipo: Relato de Experiência Inovadora (EI) \\ Categoria: Pesquisa e Avaliação \\ Setor Educacional: EDUCAÇÃO CONTINUADA EM GERAL
}

\begin{abstract}
RESUMO
A avaliação do ambiente online sob a ótica da usabilidade tem um papel importante no processo de aprendizagem, visto que as experiências educacionais devem estar cada vez mais próximas de uma geração acostumada aos princípios de design de games, num espaço fluido e integrado. A qualidade dos recursos educacionais é, portanto, avaliado pelo aluno não só no seu contexto pedagógico, mas também pelas suas características interacionais e de imersão experiencial. Este relato apresenta a metodologia, resultados e recomendações de um estudo de usabilidade de ambiente educacional online realizado para compreender a interação dos alunos com os recursos educacionais apresentados $e$ as interações e imersões propostas. Para o objetivo de avaliação proposto, a metodologia utilizada se mostrou eficiente na análise da usabilidade do curso, apontando a eficiência de muitos recursos criados e as necessidades de melhorias e ajustes em processos interacionais, considerados fundamentais para o continnum experiencial do aluno.
\end{abstract}

Palavras-chave: Usabilidade, casos clínicos, recursos educacionais, UX, experiência educacional, ambientes online 


\section{INTRODUÇÃO}

O Ministério da Educação entende que o estudante é o foco do processo de pedagógico e, assim, o material didático a ele direcionado deve desenvolver habilidades e competências específicas, compatível com a proposta e contexto socioeconômico do público-alvo (BRASIL, 2007). Afirma ainda que recursos educacionais devem ser estruturados em linguagem dialógica de modo a promover autonomia do estudante desenvolvendo sua capacidade para aprender e controlar o próprio desenvolvimento. Esse entendimento, quando ampliado para Educação à Distância (EAD), leva necessariamente em conta a concepção dos ambientes on-line como um fator de qualidade do processo de aprendizagem.

\section{OBJETIVOS E REFERÊNCIAL TEÓRICO}

Devido à importância do estudo das interações humanas, a International Organization for Standardization definiu em suas normas, um tópico para a definição padrão de UX ("ISO 9241-210:2010 - Ergonomics of human-system interaction -- Part 210: Humancentred design for interactive systems", 2010). Para as interações em ambiente digital, a norma ISO 9241-210:2010 trata do design centrado no ser humano, em sistemas interativos (Human-centred design for interactive systems). Ela fornece requisitos e recomendações para princípios e atividades centradas no ser humano durante todo 0 ciclo de vida dos sistemas e está preocupado com maneiras pelas quais os componentes podem melhorar a interação homem-sistema. Uma das formas com as quais se mede o sucesso da aplicação e o reflexo na experiência do usuário é o teste de usabilidade.

O conceito de usabilidade se refere quão fácil é a compreensão e uso de algo e seus componentes básicos são: a facilidade de aprendizado de uso, a eficiência do uso, a capacidade de memorização proveniente do uso, o número de erros durante o uso e a satisfação ao usar. De forma resumida, podemos dizer que usabilidade é a união da facilidade de uso com o prazer de usar (NIELSEN, 2012).

O estudo dos componentes de usabilidade tem um papel importante no processo de desenho de um site, como aponta Kuntz e Ulbricht (2014):

"Simplicidade e consistência são os dois principais componentes de usabilidade. Quando um site é simples, ele também torna mais rápido. Sem todo o conteúdo alheio, a página carrega mais rápido e também é mais fácil de navegar pelo conteúdo. Este princípio também se aplica ao material de aprendizagem." (KUNTZ e ULBRICHT, 2014) 
Da mesma forma como os processos educacionais devem estar mais próximos da geração acostumada aos princípios de designs de games, num espaço de aprendizagem mais fluida e integrada a uma experiência positiva de aprendizagem (MATTAR, 2014), as tecnologias usadas para os ambientes on-line de aprendizagem precisam se apropriar das ferramentas que aferem sua qualidade, entre eles a usabilidade. Kuntz e Ulbricht (2014) ressaltam que os conceitos de usabilidade na educação à distância não só tem sido pauta de discussão como são, também, considerados um critério de avaliação para sua qualidade.

Para tanto, a equipe de produção de cursos e recursos educacionais da Secretaria Executiva da Universidade Aberta do SUS se propôs a criar uma metodologia de avaliação da usabilidade dos componentes presentes nos ambientes de aprendizagem criados pelo grupo com o objetivo de otimizar a construção de experiências de aprendizagem continuada em saúde da instituição.

\section{PROCEDIMENTOS METODOLÓGICOS}

Como primeira experiência de avaliação de usabilidade de cursos da SE-UNA-SUS foi escolhido o curso de Dengue: Casos Clínicos para Atualização do Manejo, especificamente dois casos clínicos presentes: Caso Raimundo e Caso Maria do Socorro. Os casos foram acessados via Acervo de Recursos Educacionais em Saúde ARES (ALVES e colab., 2017). Assim, a usabilidade dos componentes foi observada exclusivamente em relação à navegação no caso e não contemplou o processo de inscrição/matrícula.

O segundo passo foi providenciar a estrutura física para o teste. Foi escolhida uma sala com computador e tela que reproduzisse em tempo real as ações do usuário. $O$ computador foi preparado com o software Camtasia Studio, para gravação de áudio e imagens da tela durante a interação do aluno, para posterior consulta. Assim, foi possível registrar todos os movimentos e conversas ocorridas durante os testes. Dois observadores da equipe de Produção de Cursos e Recursos Educacionais da UNA-SUS acompanhavam os testes e faziam notas num questionário estruturado.

Para a escolha dos alunos, foi identificada a quantidade de profissionais que já haviam realizado o curso. Com esses resultados, definiu-se o usuário de acordo com a representatividade profissional e idade (Figuras 1 e 2). 


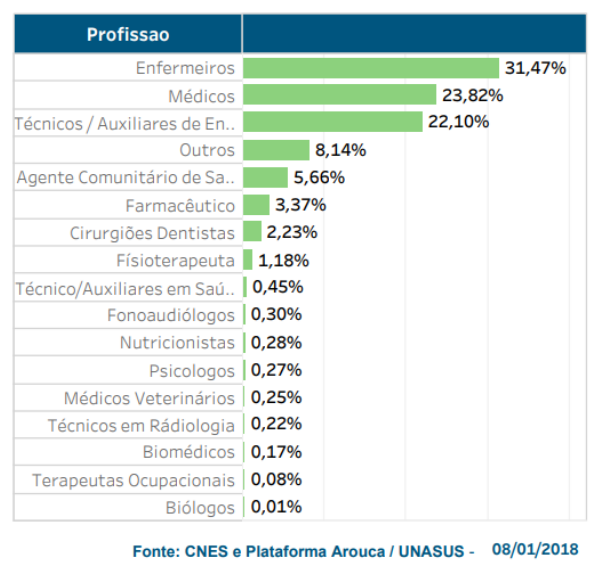

Figura 1 - Alunos do curso de Manejo Clínico da Dengue, por profissão

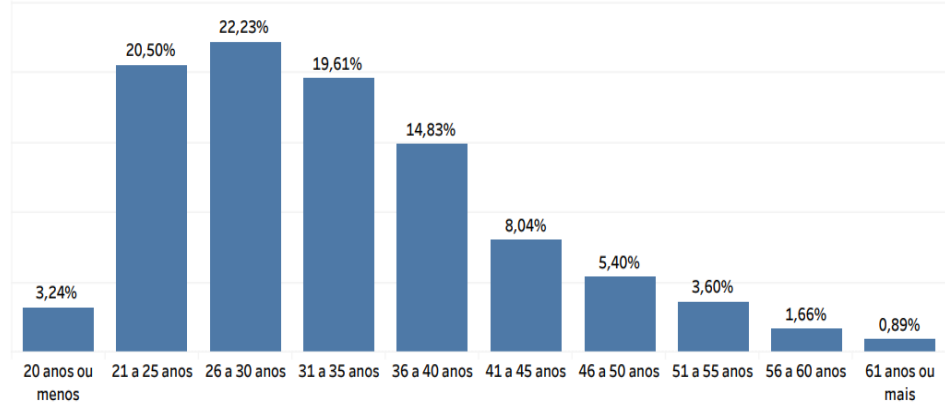

Figura 2 - Alunos do curso de Manejo Clínico da Dengue, por idade

Para evitar o conhecimento prévio do ambiente, a escolha também se restringiu ao grupo de usuários que ainda não tivessem feito o curso. Pela proximidade e pelos objetivos dessa primeira rodada de testes, todos os usuários eram do Distrito Federal. A lista dos usuários a serem convidados para o teste foi gerada a partir do banco de dados de alunos da UNA-SUS. Mais de 30 pessoas foram contatadas e cinco fizeram o teste de usabilidade - número suficiente, conforme Nielsen (2000):

- Usuário 1 - Homem, 41 anos, Fisioterapeuta e Técnico em Enfermagem atuando em hospital público do Distrito Federal e no SAMU.

- Usuário 2 - Mulher, 42 anos, Auxiliar de enfermagem, atuando em hospital público do Distrito Federal.

- Usuário 3 - Mulher, 37 anos, Enfermeira, atuando em Unidade Básica de Saúde no Distrito Federal.

- Usuário 4 - Mulher, 38 anos, Enfermeira atuando em hospital universitário no Distrito Federal.

- Usuário 5 - Mulher, 24 anos, médica Residente atuando em hospital público do Distrito Federal. 
Durante o teste, foi aplicado um roteiro de navegação cujas ações o usuário deveria seguir. Os observadores não podiam interferir nas ações nem quando solicitados pelo usuário. Ao usuário foi solicitado que expressasse verbalmente as suas ações, durante todo o processo. Ao final, foi solicitada a opinião sobre a experiência com a realização dos casos clínicos e o teste, de forma geral. Todo o objetivo do teste, bem como a gravação de áudio e vídeo foram explicados no início do procedimento e todos usuário foram solicitados a assinarem o Termo de Consentimento Livre e Esclarecido antes da realização do mesmo.

Os casos clínicos do curso Dengue: Casos Clínicos para Atualização do Manejo são dividos em partes: o relato do caso, a análise do caso clínico e as tomadas de decisão. Buscou-se avaliar a experiência do aluno em relação aos seguintes pontos:

- Sucesso ao acessar o caso clínico

- Compreensão e uso das setas de acesso aos objetivos de aprendizagem do caso; das indicações gráficas de continuidade de páginas;

- Compreensão e distinção entre os ícones clicados e não clicados do Exame Físico;

- Compreensão e uso dos tooltips;

- Compreensão acerca do armazenamento de informações na área Ficha do Paciente;

- Utilização dos botões: Avançar; Tomada de Decisão;

- Uso do botão Ficha do Paciente, durante a tomada de decisão;

- Uso do botão fluxograma, durante a tomada de decisão;

- Uso do botão Fluxograma, durante o feedback;

- Compreensão e uso das setas de retorno, durante a tomada de decisão;

- Clique nos termos em destaque;

- Uso do recurso vídeo, na conclusão do caso;

- Forma de acesso para o caso seguinte;

\section{APRESENTAÇÃO E DISCUSSÃO DOS RESULTADOS}

Após realização os testes e tabulação, a análise dos resultados foi dividida em três áreas de interesse para a usabilidade do caso clínico em questão: (i) acesso, (ii) navegação no relato, exame físico, tomada de Decisão e (iii) Termos em destaque, Conclusão do caso e Material de apoio.

Em relação ao acesso, todos os usuários tiveram facilidade de encontrar o caso na página de apresentação, com uma média de dois segundos para essa ação. Porém, os 
usuários não liam os objetivos de aprendizagem na sua totalidade. Apenas uma pessoa clicou no Leia Mais para acessar a informação completa (Figura 3).

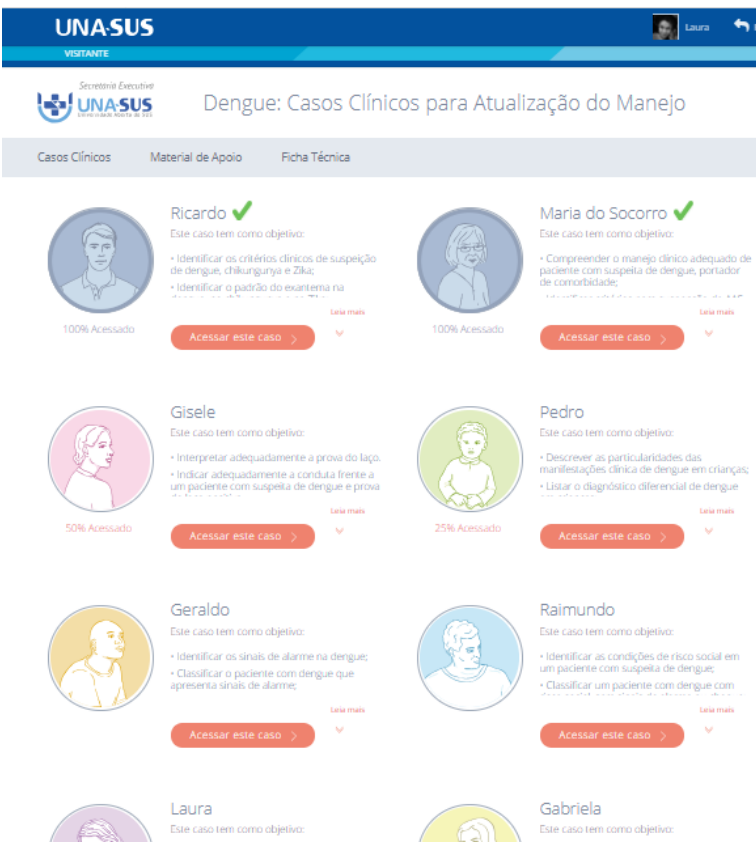

Figura 3 - Página de acesso ao caso e botão Leia Mais

O relato do caso foi lido em todos os testes. O uso das setas foi facilmente compreendido, porém a ação no botão corre apenas no segundo clique - sendo o primeiro apenas de ativação do botão. Este comportamento causou estranhamento por parte dos usuários. Em relação às indicações gráficas de continuidade foram compreendidas por todos os usuários.

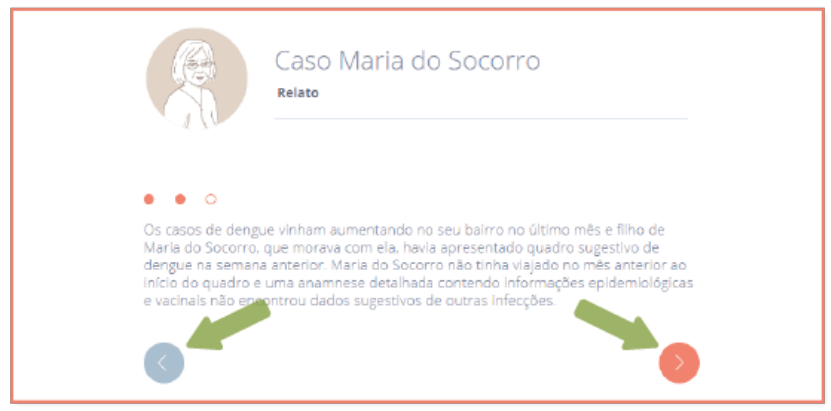

Figura 4 - Indicações gráficas de andamento

Uma das considerações e recomendações dos usuários foi em relação ao acesso ao relato do caso durante a tomada de decisão, quando eles precisavam das explicações do relato e voltavam ao ínicio. Os usuários indicaram que relato deveria ter mais fácil acesso durante a atividade, a exemplo da ficha do paciente. 
Quatro pessoas não conseguiram compreender e distinguir ícones clicados de não clicados (Figura 5). Os observadores relataram que, em virtude da dificuldade de entender os signos gráficos fazia com que houvesse demora no acesso ao conteúdo. Essa demora não se repetia ao fazer o segundo caso, quando os usuários já haviam vencido a curva de aprendizagem dos significados.

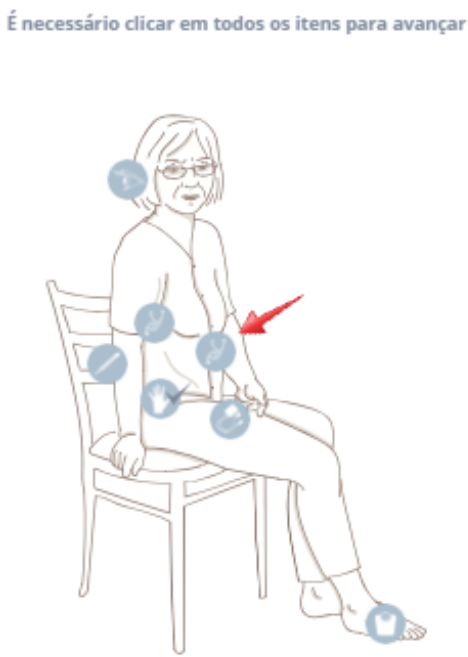

Figura 5 - Ícones do exame físico

Nesse momento também, houve a tentativa de passar para a próxima fase, mesmo sem clicar em todos os itens, o que deixou evidente a não identificação de alguns dos ícones obrigatórios presentes. Outro ponto de alerta durante a usabilidade da área de Exame Físico é a consulta. Quando o usuário precisava consultar novamente o exame, era necessário clicar em todos os ícones, mesmo os já consultados. A necessidade dessas ações repetidas - e já antes realizadas - refletiu num sentimento de frustração e desgosto, externado verbalmente, durante o teste.

Ao contrário, nessa mesma área, houve a compreensão e uso dos tooltips por todos. Os usuários também entenderam o armazenamento das informações na Ficha do Paciente e elogiaram a possibilidade de reunir e dar fácil acesso às informações úteis.

Todos os usuários clicaram no botão Tomada de decisão para prosseguir. Vale ressaltar que os observadores perceberam dúvidas sobre o resultado da ação ao clicar no botão, pois a expressão "Tomada de decisão" não representava uma atividade, dentro dos seus conceitos terminológicos. Nesse ambiente de atividades, duas pessoas não identificaram o acesso à Ficha do Paciente, material de consulta para responder às questões. Ao contrário, todos identificaram o acesso ao botão Fluxograma. Outro local onde o botão Fluxograma está presente é na área de feedback das questões. Esperava- 
se que o usuário acessasse o botão nessa área para entender o feedback de uma questão errada e pudesse tomar a decisão correta. Porém, a maioria optou por rever as alternativas sem clicar no material.

Em relação à iconografia das setas de retorno, os usuários que usaram na primeira opção (retorno para o início do caso) (Figura 6), esperavam retornar ao início caso, mas ficaram surpresos e confusos com a mensagem de retorno que, ao se encontrar no início do caso, recebiam.

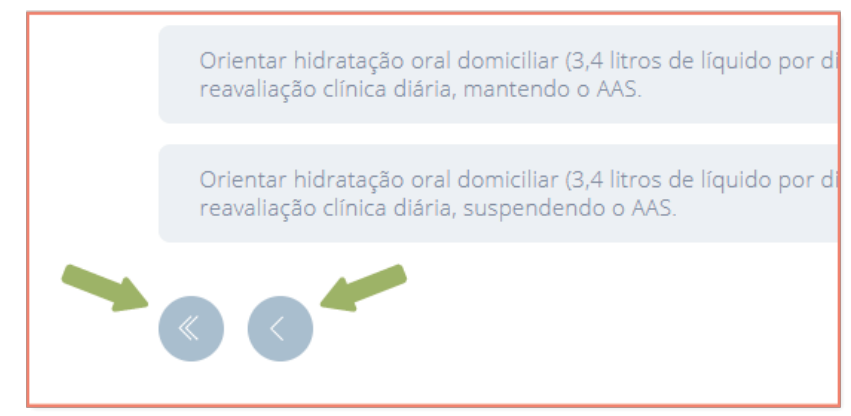

Figura 6 - Setas de retorno durante a Tomada de decisão

Em relação aos feedbacks, observou-se que os usuários ficaram confusos e não identificaram de imediato se haviam acertado ou errado a resposta. Ainda no feedback, e em relação aos termos em destaque, eles não identificaram a mudança da cor da letra como clicável (Figura 7).

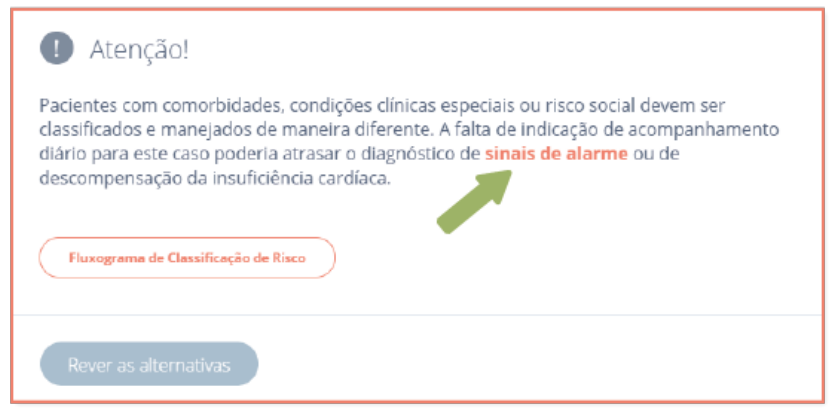

Figura 7 - Termos clicáveis do feedback

Um ponto crítico identificado durante o acesso a materiais complementares e frequente no acesso ao botão Fluxograma, foi o retorno para o ambiente do curso. O material complementar é apresentado em forma de modal (Figura 8) e o retorno para o ambiente do curso deve ser feito com um clique fora do modal ou no botão Fechar, que se localizavam ao final do modal. Contudo, esse comportamento não foi identificado pelos usuários, que buscavam um botão ou sinal de "Fechar". Ao não encontrar um botão 
semelhante, a totalidade optou por voltar do navegador ou voltar do AVA do curso. Os resultados inesperados causaram irritação - . no primeiro botão, a resposta é o retorno a página do navegador visitada antes do curso e, no segundo, a página do curso, no ARES.

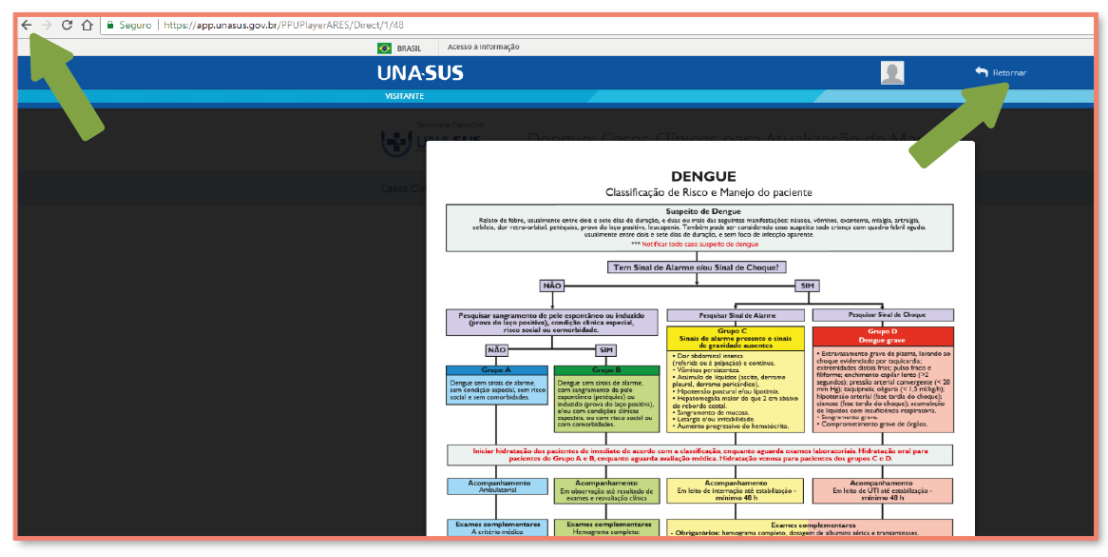

Figura 8 - Modal do fluxograma e os botões mais utilizados pelos usuários para fechá-la

O vídeo de final de caso foi assistido na sua integralidade e, na sequência, todos encontraram o próximo caso a ser visitado, no menu indicativo (Figura 9).

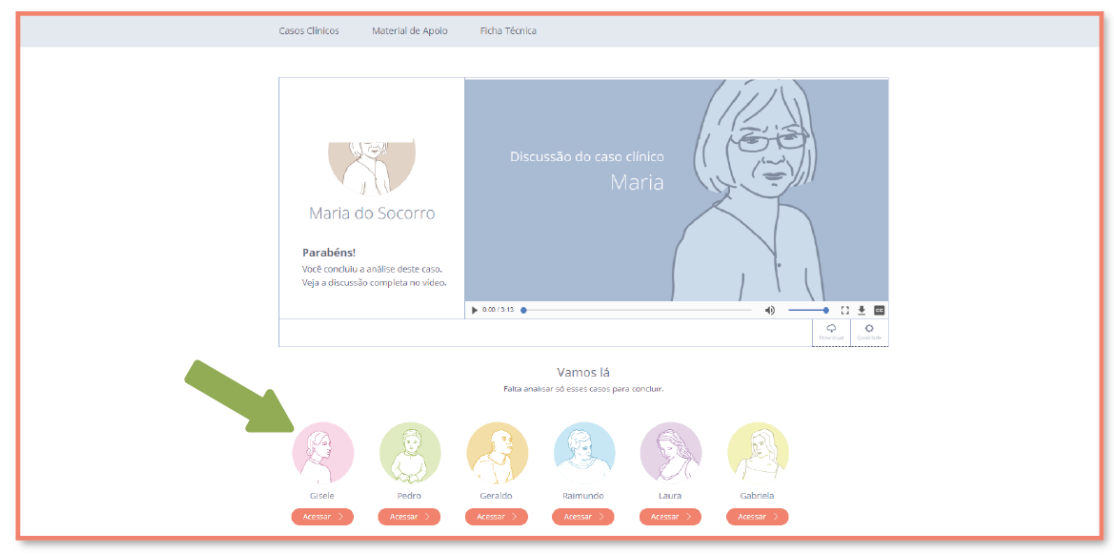

Figura 9 - Vídeo de conclusão do caso e menu indicativo para outros casos do curso

\section{CONCLUSÕES FINAIS}

A dificuldade de compreensão e distinção entre sinais gráficos em momentos fundamentais do curso, como o Exame Físico mostra o quão fundamental é o teste de usabilidade para o desenho da experiência educacional em meios digitais. Mesmo a utilização de sinais universais em relação aos exames e o símbolo de "checado", a interpretação do conjunto não está de acordo com o desenhado no processo educacional. 
A identificação dos locais certos para os conteúdos certos, realizada por meio de uma análise integrada entre arquitetura de informação e objetivos de aprendizagem é fundamental, haja vista a resposta em relação ao link do fluxograma no espaço de feedback - um edujunk (MATTAR, 2014) - o qual poderia ser removido, sem prejuízo na usabilidade do caso clínico.

A exemplo do ícone de duplas setas (Figura 6), é fundamental ter atenção aos ícones usados e aos comportamentos/ações que eles devem desencadear, pois eles devem estar em consonância com o esperado pelo usuário e, assim, evitar quebra de expectativa e falhas de usabilidade. Da mesma forma que para as imagens, a atenção à terminologia - à exemplo do não entendimento da expressão Tomada de decisão - deve estar dentro do vocabulário do usuário dentro do contexto educacional esperado.

\section{REFERÊNCIAS}

ALVES, Luciana Dantas Soares; MOURA, Alexandre Sampaio; UNA-SUS, Universidade Aberta do Sistema Único de Saúde-. Dengue: casos clínicos para atualização do manejo. Disponível em: . Acesso em: 20 mai 2018.

BARKER, Larry. Communication. 4. ed. [S.I.]: Prentice Hall, 2002.

BRASIL, Ministério da Educação. Secretaria de Educação a Distância. Referenciais de qualidade para educação superior a distância. Brasília: MEC/SEED, 2007.

ISO 9241-210:2010 - Ergonomics of human-system interaction -- Part 210: Humancentred design for interactive systems. Disponível em: . Acesso em: 6 mai 2017.

MATTAR, João. Design Educacional: educação a distância na prática. 1. ed. São Paulo: Artesanato Educacional, 2014.

NIELSEN, Jakob. Usability 101: Introduction to Usability. Disponível em: . Acesso em: 4 abr 2018.

NIELSEN, Jakob. Why You Only Need to Test with 5 Users. Nielsen Norman Group, 19 Mar 2000. Disponível em: . Acesso em: 20 mai 2018. 